\title{
Direct x-ray detection with conjugated polymer devices
}

\author{
F. A. Boroumand, M. Zhu, A. B. Dalton, J. L. Keddie, and P. J. Sellin ${ }^{\text {a) }}$ \\ Department of Physics, University of Surrey, Guildford, Surrey GU2 7XH, United Kingdom \\ J. J. Gutierrez \\ Department of Chemistry, University of Texas Pan-American, Edinburg, Texas 78541
}

(Received 6 October 2006; accepted 21 May 2007; published online 18 July 2007)

\begin{abstract}
The authors report the first direct detection of x-ray induced photocurrents in thick films (up to $20 \mu \mathrm{m}$ ) of conjugated polymers. Schottky-based "sandwich" structures were fabricated from layers of either poly[1-methoxy-4-(2-ethylhexyloxy)-phenylenevinylene] (MEH-PPV) or poly(9,9-dioctylfluorene) (PFO) on indium tin oxide substrates using a top contact of aluminum. Good rectification was achieved from the Al-polymer contact, with a reverse bias leakage current density as low as $4 \mathrm{nA} / \mathrm{cm}^{2}$ at an electric field strength of $25 \mathrm{kV} / \mathrm{cm}$. Irradiation with $\mathrm{x}$-rays from a $50 \mathrm{kV}$ x-ray tube produced a linear increase in photocurrent over a dose rate range from 4 to $18 \mathrm{mGy} / \mathrm{s}$. The observed x-ray sensitivities of $240 \mathrm{nC} / \mathrm{mGy} / \mathrm{cm}^{3}$ for $\mathrm{MEH}-\mathrm{PPV}$ and $480 \mathrm{nC} / \mathrm{mGy} / \mathrm{cm}^{3}$ for PFO structures are comparable to that reported for Si devices. A response time of $<150 \mathrm{~ms}$ to pulsed $\mathrm{x}$-ray irradiation was measured with no evidence of long-lived current transients. Conjugated polymers offer the advantage of easy coatability over large areas and on curved surfaces. Their low average atomic number provides tissue-equivalent dosimetric response, with many potential applications including medical x-ray and synchrotron photon detection. (C) 2007 American Institute of Physics. [DOI: 10.1063/1.2748337]
\end{abstract}

In the past two decades, conjugated polymers have been employed in the fabrication of light-emitting diodes, ${ }^{1}$ fieldeffect transistors, ${ }^{2}$ photovoltaic devices, ${ }^{3}$ and superconductors. ${ }^{4}$ The advantages of polymers over conventional inorganic semiconductors are their relatively low cost, suitability for both large areas and nanoscale applications, ${ }^{5}$ mechanical flexibility, and most importantly, the potential for printable electronic circuits for integrated plastic electronics. ${ }^{6}$ The use of conjugated polymers ${ }^{7}$ for ionizing radiation detection is likewise expected to offer several advantages in comparison to silicon, which is the most commonly used semiconductor for high fluence x-ray detection, e.g., at synchrotron sources or for medical dosimetry. Unlike silicon, polymers can be coated over large areas and onto curved surfaces through deposition from solutions in volatile solvents, such as in dip coating, spin casting, and ink-jet printing. Furthermore, polymers have a low average atomic number, which makes them equivalent to human tissue when used in x-ray dosimetry in clinical applications.

Despite these potential advantages, very little attention has been paid to the application of polymers in direct chargebased radiation detection, as opposed to passive thermoluminescent or optical dosimeters. Early studies in the 1950s of insulating polymers, such as poly(methyl methacrylate) and polyethylene, as tissue-equivalent $\mathrm{x}$-ray dosimetry detectors ${ }^{8}$ concluded that the combination of very low mobilities and short carrier lifetimes severely limited their x-ray sensitivity. More recently, alpha particle sensitivity has been demonstrated from polyactylene sheets which showed drift mobilities of $10^{-4}$ and $10^{-3} \mathrm{~cm}^{2} / \mathrm{V} \mathrm{s}$ for electrons and holes, respectively. ${ }^{9}$ With such a relatively low mobility, when such a material is used in a detector, it must be kept rather thin in order to extract a useful current. However, there is a trade-off

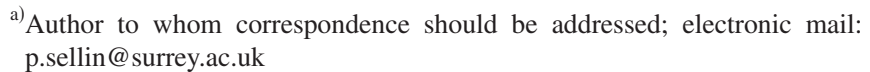

against the requirement to use a thicker detection layer to achieve a sufficient interaction volume. For x-ray dosimetry use a polymer-based detector should have a sensitivity comparable to that of silicon, which is typically of the order of $300 \mathrm{nC} / \mathrm{mGy} / \mathrm{cm}^{3}{ }^{10}$

In this letter, we present the first report of the directly generated $\mathrm{x}$-ray photocurrent response of conjugated polymers. We use poly[1-methoxy-4-(2-ethylhexyloxy)phenylenevinylene] (MEH-PPV) whose charge transport properties have been extensively studied elsewhere. ${ }^{11,12}$ MEH-PPV was synthesized following a procedure reported in the literature. ${ }^{13,14}$ Its molecular weight, determined via gel permeation chromatography, is $2.85 \times 10^{5} \mathrm{~g} \mathrm{~mole}^{-1}$, with a polydispersity index of 1.87 . Additionally, we use poly(9,9dioctylfluorenyl-2,7-diyl) (PFO), which is a promising material for blue emission light-emitting diodes. ${ }^{15}$ It was obtained from American Dye Source, Inc. and used as received.

High electric field strengths are necessary to maximize the displacement current from the drifting charge carriers, so requiring a high quality rectifying junction with low reverse bias leakage current. Good rectification has been demonstrated for Schottky contacts on MEH-PPV using various higher work-function metals, including $\mathrm{Al}(4.4 \mathrm{eV})$ and $\mathrm{Au}$ $(5.2 \mathrm{eV}) .{ }^{16}$ For indium tin oxide (ITO)/MEH-PPV/Al devices, the barrier height for electron injection from $\mathrm{Al}$ is $1.4 \mathrm{eV}$, and for hole injection from ITO it is $0.6 \mathrm{eV}$. When operated in reverse bias (with $\mathrm{Al}$ as the cathode), leakage currents of the order of $10 \mathrm{nA} / \mathrm{cm}^{2}$ are observed in thin devices, which are predominantly due to thermionic emission. $^{17,18}$

For efficient operation as an x-ray detector, thick polymer layers (i.e., $>10 \mu \mathrm{m}$ ) are required to maximize the $\mathrm{x}$-ray photon attenuation. In previous work, conjugated polymers have not been deposited as such thick layers, as these are not required for optoelectronic or photovoltaic applications. Our $\mathrm{x}$-ray detector structures were fabricated by dropcasting 


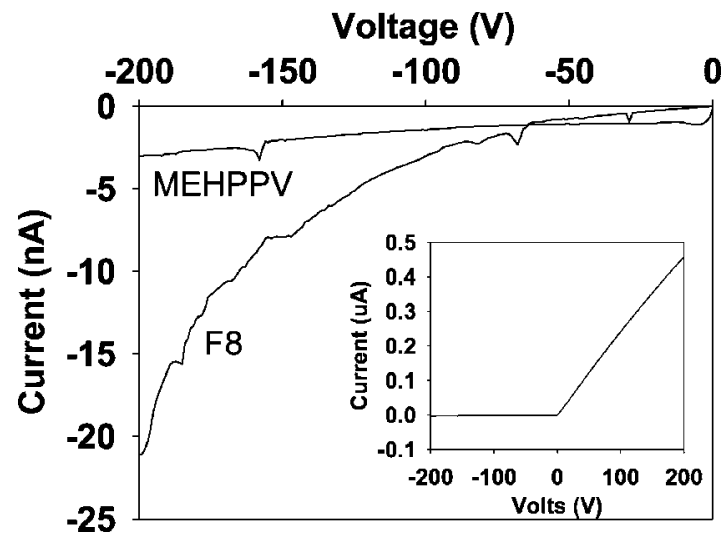

FIG. 1. I- $V$ characteristics of MEH-PPV and PFO devices at reverse bias voltages. Inset shows the rectifying behavior for MEH-PPV over a DC range from -200 to $+200 \mathrm{~V}$.

polymer solutions in toluene onto an ITO-coated glass substrate. To form a rear contact with the ITO, a $70 \mathrm{~nm}$ thick layer of the hole-injecting polymer blend poly(3,4-ethylenedioxythiophene)/poly(styrene-sulphonic acid) (PEDOT:PSS), supplied by HC Starck (Germany), was first spin cast onto the ITO-coated glass substrates (5000 rpm for $30 \mathrm{~s}$ ). The PEDOT:PSS films were baked in air for $15 \mathrm{~min}$ at $130{ }^{\circ} \mathrm{C}$. The active region of the device was then fabricated through the successive drop casting of approximately $2 \mu \mathrm{m}$ films of either PFO or MEH-PPV to create a thick layer. The polymer concentration in the toluene solutions were $1.33 \%$ and $0.66 \%$ by weight for PFO and MEH-PPV, respectively. After each drop casting, the film was annealed at $120^{\circ} \mathrm{C}$ in air for $15 \mathrm{~min}$, to eliminate solvent and to allow good interface formation between the films. The thick layers consisted of up to eight films, making an average total thickness on the order of $20 \mu \mathrm{m}$ for the stack. The roughness of the final surface of the PFO was relatively smooth but MEH-PPV showed a very nonuniform surface with a small number of peaks in excess of $100 \mu \mathrm{m}$, according to surface profilometry (Veeco Dektak). Finally, a square $\left(5 \times 5 \mathrm{~mm}^{2}\right) \mathrm{Al}$ cathode (thickness of $100 \mathrm{~nm}$ ) was thermally evaporated onto the polymer layer using a metal shadow mask.

The $\mathrm{x}$-ray photocurrent measurements were carried out using an Oxford Instrument XF5011 $50 \mathrm{kV}$ x-ray tube with a molybdenum target, which produced a maximum $1 \mathrm{~mA}$ current. The $I-V$ characteristics in the dc and x-ray stimulated modes were measured by an automated Keithley 487 combined picoammeter and voltage source. All measurements were carried out in air.

The electrical performance of the Schottky junction for both the MEH-PPV and PFO thick film devices was investigated at high field strength. Figure 1 compares the reverse dc characteristics of both devices in the range from zero to $-200 \mathrm{~V}$. Both devices show extremely low current densities at $-200 \mathrm{~V}$ (corresponding to a mean field strength in the range of $100-200 \mathrm{kV} / \mathrm{cm}$ ), which is an essential requirement for operation as an x-ray photoconductor. At $-200 \mathrm{~V}$, current densities of 12 and $88 \mathrm{nA} / \mathrm{cm}^{2}$ were observed for MEH-PPV and PFO, respectively. These compare favorably with the reverse bias current density of $100 \mathrm{nA} / \mathrm{cm}^{2} \mathrm{ob}-$ served at $50 \mathrm{kV} / \mathrm{cm}$ in much thinner $(800 \mathrm{~nm})$ ITO/MEHPPV/Al luminescent devices. ${ }^{17}$ The inset $I-V$ curve for MEHPPV from -200 to $+200 \mathrm{~V}$ shows the good rectification behavior of the device. The forward bias current has a linear Downloaded 30 Mar 2009 to 131.227.178.132. Redistribution subje
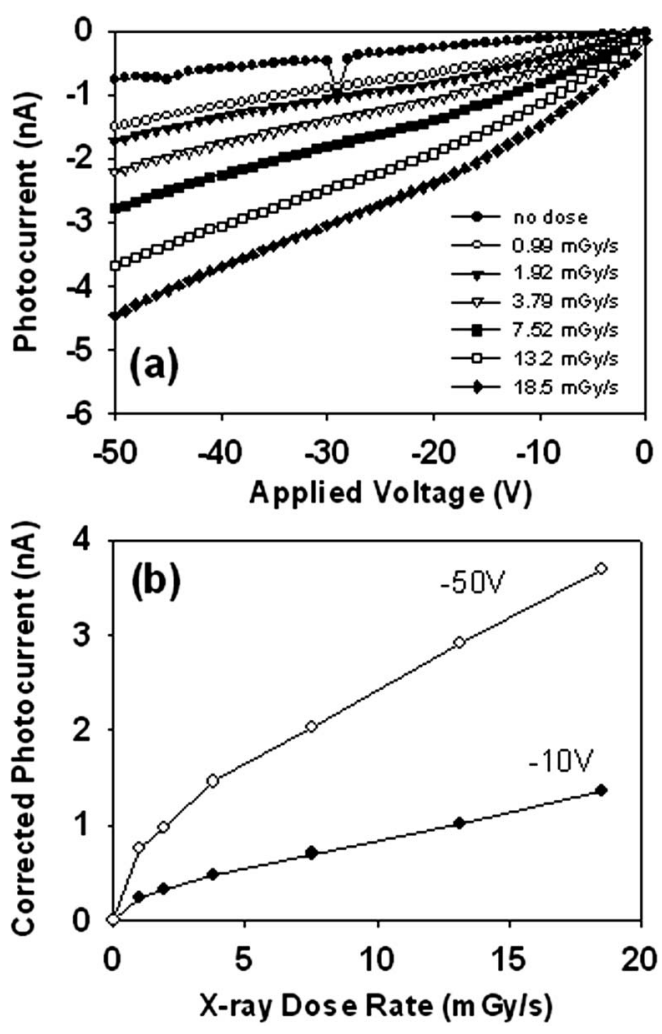

FIG. 2. X-ray response for PFO device. (a) $I-V$ characteristics for variable $\mathrm{X}$-ray dose rate, and (b) deduced photocurrent of the device from (a) at $-10 \mathrm{~V}$ and $-50 \mathrm{~V}$.

form over this voltage range and is dominated by the high series resistance of the thick polymer layer, which limits the forward bias current to $<0.5 \mu \mathrm{A}$. Furthermore, a comparison between the devices indicates that for voltages below $-60 \mathrm{~V}$, PFO shows lower leakage current of less than $2 \mathrm{nA}$ and then increasing sharply to $20 \mathrm{nA}$ at $-200 \mathrm{~V}$, while MEH-PPV has a stable dark current between 1 and $3 \mathrm{nA}$ over the whole range.

Figure 1 demonstrates that a multilayer MEH-PPV structure can exhibit good electrical properties and can preserve the high rectification which is observed for thinner singlelayer MEH-PPV devices. Both devices show a reverse bias leakage current which increases slowly with field strength, although this increase is notably higher in the PFO device. We note that similar nonsaturation of the reverse bias current has been reported in ITO/MEH-PPV/Al devices, due to the image-force lowering of the Schottky barrier height. ${ }^{17}$

Figure 2 shows the dc and $\mathrm{x}$-ray response of the PFO device, for an applied voltage range of up to $-50 \mathrm{~V}$. Part (a) represents the X-ray induced photocurrent-voltage of the device as a function of $x$-ray dose rate. Part (b) shows the photocurrent-dose behavior and calculated sensitivity of the detector to x-ray irradiation at certain bias voltages.

Figure 2(a) shows a systematic increase in photocurrent as a function of increasing $\mathrm{x}$-ray dose rate, up to $18.5 \mathrm{mGy} / \mathrm{s}$. At lower dose rates, the photocurrent increases linearly with applied voltage, whereas some reduction in the gradient of the photocurrent is observed for higher dose rates above $-15 \mathrm{~V}$. At $-50 \mathrm{~V}$ the photocurrent increases by a factor of 5 from the dark current value of $0.9 \mathrm{nA}$ at zero dose rate, to $4.5 \mathrm{nA}$ at a dose rate of $18.5 \mathrm{mGy} / \mathrm{s}$. Figure 2(b) is calculated from Fig. 2(a) and shows the linear behavior of the corrected photocurrent as a function of dose rate in the to AIP license or copyright; see http://apl.aip.org/apl/copyright.jsp 


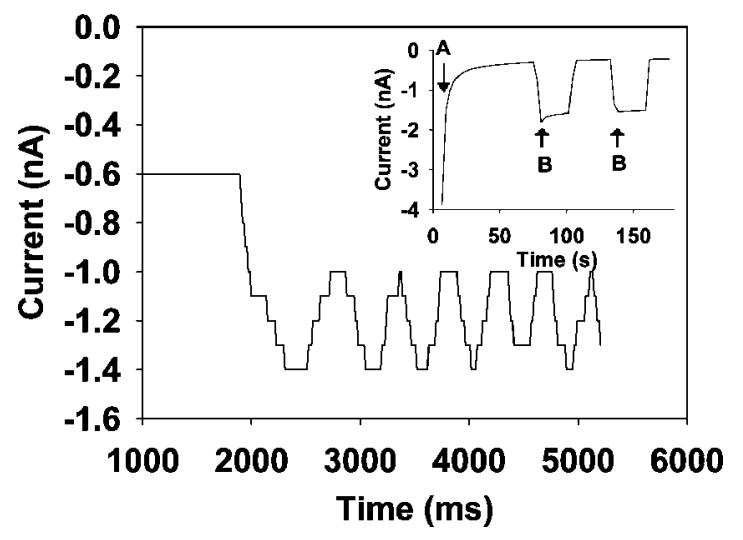

FIG. 3. Dynamic monitoring of x-ray dose using an MEH-PPV detector with the application of a slowly rotating slotted collimator. Inset shows a static situation where the x-ray source is switched on and off every few seconds.

range from 4 to $18 \mathrm{mGy} / \mathrm{s}$. The photocurrent has been corrected by subtracting the dark current at zero dose. The slope of these data gives the x-ray dose sensitivity $S$ of the device (in $\mathrm{C} / \mathrm{Gy}$ ), defined as

$$
S=\frac{I_{C}}{D}
$$

where $I_{C}$ is the corrected photocurrent and $D$ is the dose rate in $\mathrm{Gy} / \mathrm{s}$.

At a bias voltage of $-10 \mathrm{~V}$, the sensitivity of the PFO device to $\mathrm{x}$-rays for the linear part of the graph is calculated as $0.064 \mathrm{nC} / \mathrm{mGy}$, which increases to $0.24 \mathrm{nC} / \mathrm{mGy}$ at $-50 \mathrm{~V}$. Expressed in terms of sensitivity per unit volume, this corresponds to $128-480 \mathrm{nC} / \mathrm{mGy} / \mathrm{cm}^{3}$, which compares well with silicon devices [up to $500 \mathrm{nC} / \mathrm{mGy} / \mathrm{cm}^{3}$ (Ref. 10)]. Since there is no evidence of saturation in the photocurrent at high bias, the device sensitivity will presumably increase further at higher applied field strengths. Similar $I-V$ photocurrent data are obtained as a function of dose rate for the MEH-PPV device. This device shows similar behavior to the PFO device although the level of dark current is approximately $50 \%$ higher over the whole of the measured voltage range. At $-10 \mathrm{~V}$ bias the MEH-PPV device gives a sensitivity of $0.1 \mathrm{nC} / \mathrm{mGy}$ (equivalent to $200 \mathrm{nC} / \mathrm{mGy} / \mathrm{cm}^{3}$ ), which is marginally higher than for the $\mathrm{PFO}$ device under the same bias conditions.

Figure 3 shows the time response of the $\mathrm{x}$-ray photocurrent measured from the MEH-PPV device using a modulated $\mathrm{x}$-ray beam. The beam modulation was achieved using a slowly rotating six-bladed metal chopper wheel. The thickness of the metal blades was sufficient to attenuate approximately $50 \%$ of the x-ray dose. In the main plot in Fig. 3, the $\mathrm{x}$-ray beam is switched on at an arbitrary time marker of $1800 \mathrm{~ms}$. The measured current increases from a dark current of $0.6 \mathrm{nA}$ to a photocurrent of $1.4 \mathrm{nA}$. The bias voltage was kept constant at $-10 \mathrm{~V}$. With the wheel turning, the $\mathrm{x}$-ray photocurrent is clearly modulated with a period of $\sim 0.5 \mathrm{~s}$. Based on these data, an estimate of the response time of the detector is faster than $150 \mathrm{~ms}$.

The inset in Fig. 3 is the photocurrent response for the MEH-PPV device, initially at zero bias. A bias of $-10 \mathrm{~V}$ is applied at point $A$, and after an initial relaxation, a steady state current is observed. At point $B$, the x-ray beam is turned on with a dose rate of $18.5 \mathrm{mGy} / \mathrm{s}$, resulting in an increase in the photocurrent. Subsequently, when the beam is switched off, the current reduces to the original value. Note that the shape of the "relaxation" is preserved even during the switching on and off of the beam, indicating that the $\mathrm{x}$-ray induced increase in the photocurrent is independent of the dark current level. After prolonged exposure times, there is no observable loss of $\mathrm{x}$-ray sensitivity, indicating that the polymer shows no sign of radiation damage for doses in excess of $10 \mathrm{~Gy}$.

In summary, the direct detection of x-ray induced photocurrents has been achieved in two different conjugated polymers. In each polymer, good x-ray sensitivity and linearity were achieved for dose rates up to $18 \mathrm{mGy} / \mathrm{s}$, demonstrating their applicability as organic direct-detection x-ray sensors. Although the carrier mobilities for PFO are expected to be about two orders of magnitude higher than that for MEH-PPV, ${ }^{19,20}$ there is no marked difference in device performance between the two devices. In future work, increases in film thickness, and the use of the next generation of higher mobility conjugated polymers, will greatly increase the potential for $\mathrm{x}$-ray imaging applications, such as in the security and medical sectors. Appropriate processing of the polymer will enable the production of fibers in "active" textile radiation dosimeters, such as in "detector clothing" for workers at risk of exposure to radiation.

The authors acknowledge financial support from the U.K. PPARC through Grant No. PPA/G/S/2003/00158. They also thank David G. Lidzey (University of Sheffield) for providing the PFO and PEDOT:PSS, and David Garrity and Izabela Jurewicz (University of Surrey) for their help with the $\mathrm{x}$-ray measurements.

${ }^{1}$ N. Tessler, N. T. Harrison, and R. H. Friend, Adv. Mater. (Weinheim, Ger.) 10, 64 (1998).

${ }^{2}$ F. Garnier, Electronic Materials (Wiley-VCH Weinheim, 1998), p. 559.

${ }^{3}$ K. M. Coakley and M. D. Mc Gehee, Chem. Mater. 16, 4533 (2004).

${ }^{4}$ A. Pron and P. Rannou, Prog. Polym. Sci. 27, 135 (2002).

${ }^{5}$ F. A. Boroumand, P. W. Fry, and D. G. Lidzey, Nano Lett. 5, 67 (2005).

${ }^{6}$ H. Sirringhause, N. Tessler, and R. H. Friend, Science 280, 1741 (1998).

${ }^{7}$ D. Natali and M. Sampietro, Nucl. Instrum. Methods Phys. Res. A 512, 419 (2003).

${ }^{8}$ J. F. Fowler, Proc. R. Soc. London, Ser. A 236, 464 (1956).

${ }^{9}$ P. Beckerle and H. Strobele, Nucl. Instrum. Methods Phys. Res. A 449, 302 (2000).

${ }^{10}$ M. Bruzzi, F. Nava, S. Pini, and S. Russo, Appl. Surf. Sci. 184, 425 (2001).

${ }^{11}$ A. R. Inigo, H. Chiu, W. Fann, Y. Huang, U. S. Jeng, C. H. Hsu, K. Peng, and S. Chen, Synth. Met. 139, 581 (2003).

${ }^{12}$ F. Feller, D. Geschke, and A. P. Monkman, J. Appl. Phys. 93, 2884 (2003).

${ }^{13}$ C. J. Neef and J. P. Ferraris, Macromolecules 33, 2311 (2000).

${ }^{14}$ J. J. Gutierrez, N. Luong, D. Zepeda, and J. P. Ferraris, Polym. Prepr. (Am. Chem. Soc. Div. Polym. Chem.) 45, 172 (2004).

${ }^{15}$ A. W. Grice, D. D. C. Bradley, M. T. Bernius, M. Inbasekaran, W. W. Wu, and E. P. Woo, Appl. Phys. Lett. 73, 629 (1998).

${ }^{16}$ I. D. Parker, J. Appl. Phys. 75, 1656 (1994).

${ }^{17}$ S. Karg, M. Meier, and W. Reiss, J. Appl. Phys. 82, 1951 (1997).

${ }^{18}$ P. S. Davids, I. H. Campbell, and D. L. Smith, J. Appl. Phys. 82, 6319 (1997).

${ }^{19}$ I. H. Campbell, D. L. Smith, C. J. Neef, and J. P. Ferraris, Appl. Phys. Lett. 74, 2809 (1999).

${ }^{20}$ M. Redecker, D. D. C. Bradley, M. Inbasekaran, and E. P. Woo, Appl. Phys. Lett. 73, 1565 (1998). 